Marquette University

e-Publications@Marquette

7-9-2018

\title{
Molecular Actuators in Action: Electron-Transfer-Induced Conformation Transformation in Cofacially Arrayed Polyfluorenes
}

\author{
Denan Wang \\ Marquette University, denan.wang@marquette.edu \\ Marat R. Talipov \\ Marquette University, marat.talipov@marquette.edu \\ Maxim Vadimovich Ivanov \\ Marquette University \\ Saber Mirzaei \\ Marquette University \\ Sergey V. Lindeman \\ Marquette University, sergey.lindeman@marquette.edu
}

See next page for additional authors

Follow this and additional works at: https://epublications.marquette.edu/chem_fac

Part of the Chemistry Commons

\section{Recommended Citation}

Wang, Denan; Talipov, Marat R.; Ivanov, Maxim Vadimovich; Mirzaei, Saber; Lindeman, Sergey V.; Cai, Sheng; Rathore, Rajendra; and Reid, Scott A., "Molecular Actuators in Action: Electron-Transfer-Induced Conformation Transformation in Cofacially Arrayed Polyfluorenes" (2018). Chemistry Faculty Research and Publications. 979.

https://epublications.marquette.edu/chem_fac/979 


\section{Authors}

Denan Wang, Marat R. Talipov, Maxim Vadimovich Ivanov, Saber Mirzaei, Sergey V. Lindeman, Sheng Cai, Rajendra Rathore, and Scott A. Reid 
Marquette University

e-Publications@Marquette

\section{Chemistry Faculty Research and Publications/College of Arts and Sciences}

This paper is NOT THE PUBLISHED VERSION; but the author's final, peer-reviewed manuscript. The published version may be accessed by following the link in th citation below.

Journal of Physical Chemistry Letters, Vol. 9, No. 15 (July 9, 2018): 4233-4238. DOI. This article is (C) American Chemical Society and permission has been granted for this version to appear in ePublications@Marquette. American Chemical Society does not grant permission for this article to be further copied/distributed or hosted elsewhere without the express permission from American Chemical Society.

\section{Molecular Actuators in Action: Electron-Transfer- Induced Conformation Transformation in Cofacially Arrayed Polyfluorenes}

Denan Wang

Department of Chemistry, Marquette University, Milwaukee, Wisconsin

Marat R. Talipov

Department of Chemistry, Marquette University, Milwaukee, Wisconsin

Maxim V. Ivanov

Department of Chemistry, Marquette University, Milwaukee, Wisconsin

Saber Mirzaei

Department of Chemistry, Marquette University, Milwaukee, Wisconsin

Sergey V. Lindeman

Department of Chemistry, Marquette University, Milwaukee, Wisconsin

Sheng Cai

Department of Chemistry, Marquette University, Milwaukee, Wisconsin Rajendra Rathore

Department of Chemistry, Marquette University, Milwaukee, Wisconsin

Scott A. Reid 


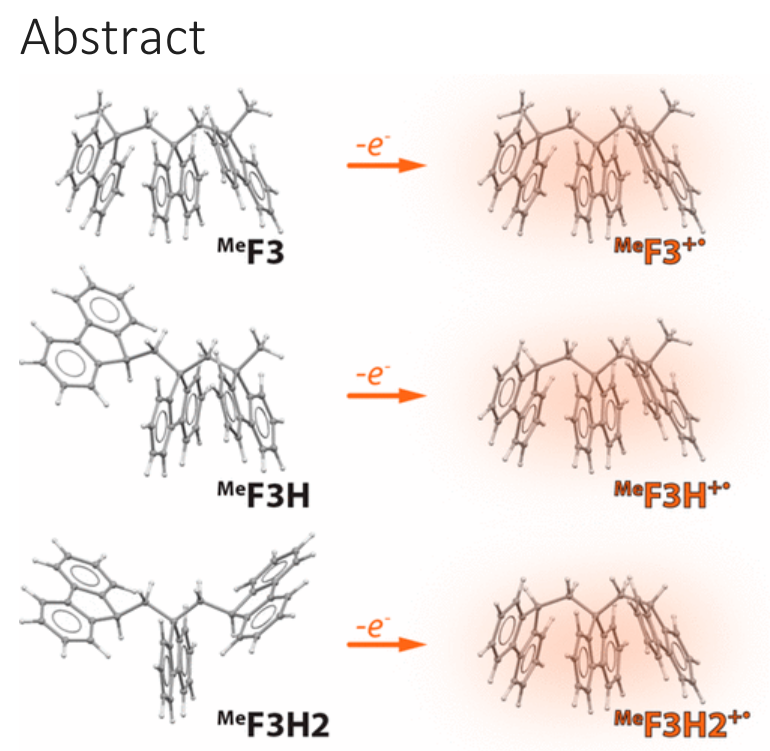

There is much current interest in the design of molecular actuators, which undergo reversible, controlled motion in response to an external stimulus (light, heat, oxidation, etc.). Here we describe the design and synthesis of a series of cofacially arrayed polyfluorenes ( ${ }^{\mathrm{Me}} \mathrm{F} n \mathrm{Hm}$ ) with varied end-capping groups, which undergo redoxcontrolled electromechanical actuation. Such cofacially arrayed polyfluorenes are a model molecular scaffold to investigate fundamental processes of charge and energy transfer across a $\pi$-stacked assembly, and we show with the aid of NMR and optical spectroscopies, X-ray crystallography and DFT calculations that in the neutral state the conformation of $\mathrm{Me}^{\mathrm{FH}} \mathrm{H} 1$ and $\mathrm{Me}^{\mathrm{F}} n \mathrm{H} 2$ is open rather than cofacial, with a conformational dependence that is highly influenced by the local environment. Upon (electro)chemical oxidation, these systems undergo a reversible transformation into a closed fully $\pi$-stacked conformation, driven by charge-resonance stabilization of the cationic charge. These findings are expected to aid the design of novel wire-like cofacially arrayed systems capable of undergo redox-controlled actuation.

The design and development of molecular actuators, which exhibit a controlled, reversible motion in response to an external stimulus, continue to attract much interest due to the extensive use of molecular actuators in such applications as biomechanical devices, $(1,2)$ molecular electronics, $(3,4)$ and supramolecular chemistry. $(5,6)$ Among various external stimuli that can induce mechanical actuation, electron transfer is of particular importance. (7-12) It is now appreciated that molecular assemblies based on the $\pi$-stacked aromatic moieties are capable of substantial charge resonance stabilization, $(13-16)$ and thus actuators based upon $\pi$ stacked assemblies hold significant promise. In addition, these molecular scaffolds often serve as synthetically designed models of naturally occurring molecular assemblies such as DNA where the paired bases are orderly stacked inside helical strands (Figure 1). 


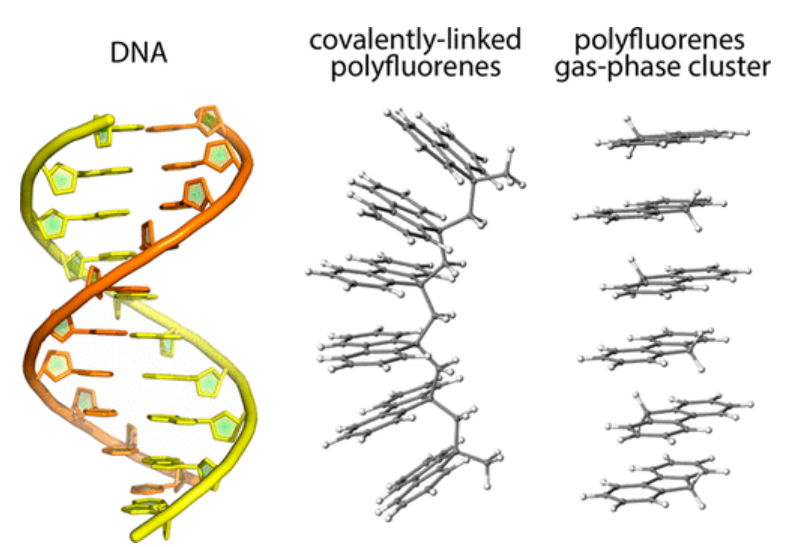

Figure 1. Structures of DNA, covalently linked $\pi$-stacked polyfluorene F6 and displaced-stacked fluorene cluster $(\mathrm{F})_{6}$.

First developed by Rathore and co-workers, $(17,18) \pi$-stacked polyfluorenes ( $F n$, Figure 1 ) have served as a model system to study fundamental process of charge/energy delocalization and transfer across a $\pi$-stacked assembly.(19-22) For example, efficient (cofacial) orbital overlap between adjacent fluorenes in Fn promotes extensive hole delocalization, as evidenced from the decreasing (adiabatic) oxidation potentials in solution and (vertical) ionization energies in gas phase with increasing number of fluorenes. $(17,23)$ In contrast to the structurally well-defined Fn series, the van der Waals clusters of fluorenes in the gas phase, i.e., $(F)_{n}$, may exist in numerous conformations stabilized by a combination of $\mathrm{CH}-\pi$ and $\pi-\pi$ interactions.(23) Yet upon ionization, configurations that consist of displaced fully $\pi$-stacked $(F)_{n}$ clusters are observed (Figure 1), suggesting the increasing role of the cofacial arrangement in the cation radical state as compared to the neutral state.(23) Indeed, it is well-known for the simplest model system, the benzene dimer, that in the neutral state a non- $\pi$-stacked conformation is preferred (i.e., T-shaped), while at the cation radical (and also at the excited state) a sandwich-like $\pi$-stacked arrangement is the global minimum.(16,24-26) In the same vein, many conformationally mobile bichromophoric actuators at neutral state exist in the (noncofacial) open conformation, yet upon ionization reorganize into a (cofacial) closed conformation.

Motivated by the importance of a polyfluorene scaffold as a model $\pi$-stacked assembly and the interest in identification of novel redox-controlled actuators, we designed a set of polyfluorenes (denoted ${ }^{\mathrm{Me}} \mathrm{F} n \mathrm{Hm}, n=1-$ $3, m=0-2$, Scheme $1 A)$ with varied end-capping groups ( $\mathrm{R}_{1 / 2}=\mathrm{H}$ or $\left.\mathrm{Me}\right)$. We will show with the aid of electrochemistry, electronic spectroscopy of polyfluorene cation radicals and DFT calculations that depending on the end-capping groups, these ${ }^{\mathrm{Me}} \mathrm{F} n \mathrm{Hm}$ assemblies in the neutral state may exist in the (noncofacial) open conformation, and upon oxidation undergo reorganization into a fully $\pi$-stacked assembly, irrespective of the end-capping groups. For example, considering a bifluorene, three neutral state conformations are possible, i.e., $\pi$-stacked, $T$-shaped, and $\mathrm{W}$-shaped. The relative energy ordering of these conformations is controlled by the end-capping group; however, upon oxidation the bifluorene is transformed into a $\pi$-stacked

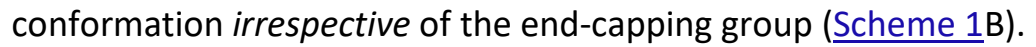

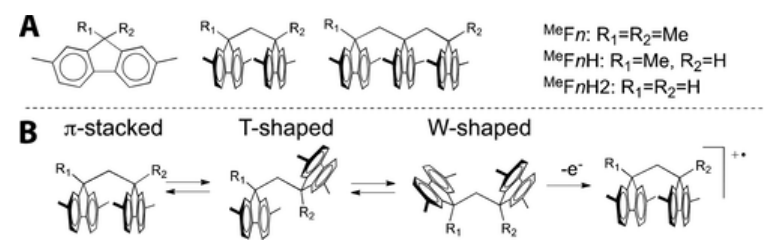

Scheme 1. (A) Structures of MeFnHm ( $n=1-3, m=0-2)$ and (B) Three Possible Conformations of F2Hm that upon Oxidation Transform into a $\pi$-Stacked Structure 
Accordingly, in this work, we demonstrate that a series of polyfluorenes ${ }^{\mathrm{Me}} \mathrm{F} n \mathrm{H} m$ undergoes a redox-controlled mechanical motion that is driven by the charge-resonance stabilization of the cationic charge between adjacent cofacially juxtaposed fluorene rings. The novel ${ }^{\mathrm{Me}} \mathrm{F} n \mathrm{Hm}$ series presents an excellent case to study the conformational transformation induced by electron transfer in extended $\pi$-stacked assemblies. These findings will aid to the design and preparation of novel multilayered $\pi$-stacked systems, which not only allow the study of charge-transfer phenomenon through stacked aromatic moieties, but will also aid to the development of (nextgeneration) conducting wire-like assemblies capable of undergoing redox-controlled actuation.

\section{Exploratory Conformational Analysis of F2, F2H, and $\mathrm{F} 2 \mathrm{H} 2$}

The bifluorene $\mathrm{F} 2$ and its derivatives with varied end-capping groups (i.e., $\mathrm{F} 2 \mathrm{H}$ and $\mathrm{F} 2 \mathrm{H} 2$ ) serve as model covalently linked systems that can be used to probe the influence of the end-capping group on the relative stability of various conformations. Initially, we performed a detailed conformation analysis of F2, F2H, and F2H2 at the M06-2X/6-31G $(\mathrm{d})+\mathrm{PCM}\left(\mathrm{CH}_{2} \mathrm{Cl}_{2}\right)$ level of theory $(27,28)$ with the aid of relaxed potential energy surface (PES) scans of dihedral angles $\theta$ and $\phi$, i.e., a pair of geometrical parameters that define the relative arrangement of two fluorenes (Figure 1A). The PES scans of each bifluorene produced contour plots (Figure 1A), where the color represents the relative energy of the bifluorene at fixed values of $\theta$ and $\phi$ with other geometrical parameters being optimized. These plots show that in all three cases at least three different conformations are possible, i.e., $\pi$-stacked, T-shaped, and $\mathrm{W}$-shaped; note that unsymmetrical F2H has two Tshaped conformations.

The calculations further predict that a (closed) $\pi$-stacked conformation of $\mathrm{F} 2$ is the global minimum structure, which is consistent with experimental NMR spectra of $\mathrm{F} 2$ in $\mathrm{CH}_{2} \mathrm{Cl}_{2}$ solution (Figure $2 \mathrm{~B}$ ) as well as with the previous studies. Once the end-capping groups are changed from bulky methyl groups into much smaller hydrogens in $\mathrm{F} 2 \mathrm{H}$ and $\mathrm{F} 2 \mathrm{H} 2$, calculations predict that (open) non $\pi$-stacked conformations become nearly isoenergetic with the $\pi$-stacked conformations (Table $\mathrm{S} 2$ in the Supporting Information). Indeed, comparison of the simulated NMR spectra of $\mathrm{F} 2 \mathrm{H}$ and $\mathrm{F} 2 \mathrm{H} 2$ with the experimental spectra showed that in solution the $\mathrm{W}$ shaped conformation is the global minimum structure for both bifluorenes (Figure 2B).

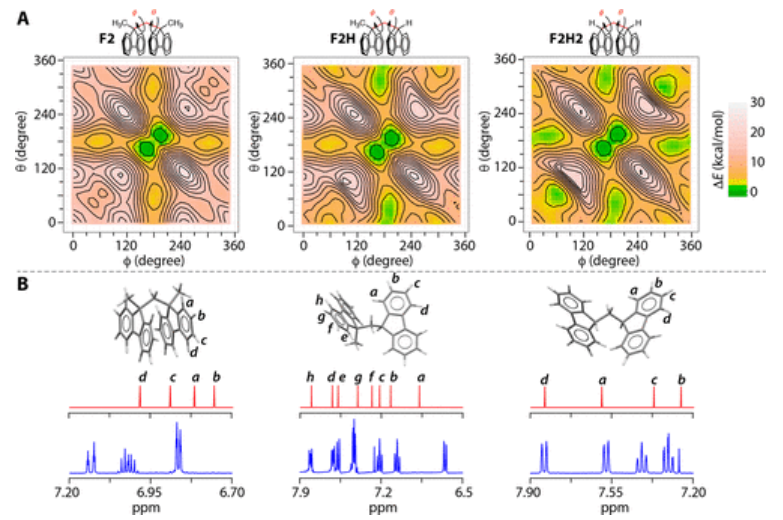

Figure 2. (A) Two-dimensional relaxed potential energy maps of $\mathrm{F} 2, \mathrm{~F} 2 \mathrm{H}$, and $\mathrm{F} 2 \mathrm{H} 2$ obtained using M06-2X/6$31 \mathrm{G}(\mathrm{d})+\mathrm{PCM}\left(\mathrm{CH}_{2} \mathrm{Cl}_{2}\right)$. Dihedral angles $\theta$ and $\phi$ were varied from $0^{\circ}$ to $360^{\circ}$ with $15^{\circ}$ step size. At each step $\theta$ and $\phi$ were fixed, while remaining geometrical parameters were optimized. (B) Calculated NMR spectra (red) of $\pi-$ stacked F2, W-shaped $\mathrm{F} 2 \mathrm{H}$, and F2H2; experimental NMR spectra (blue) of F2, $\mathrm{F} 2 \mathrm{H}$, and $\mathrm{F} 2 \mathrm{H} 2$.

Motivated by the accessibility of the open conformation in bifluorenes $\mathrm{F} 2 \mathrm{H}$ and $\mathrm{F} 2 \mathrm{H} 2$, we have synthesized the polyfluorene series ${ }^{\mathrm{Me}} \mathrm{FnHm}$ (Scheme 1A) with methyl groups at the 2, 7 positions in each fluorene, which are expected to follow the same trends in conformational stability but better stabilize the cation radical state. 


\section{Synthesis}

A series of polyfluorenes ${ }^{\mathrm{Me}} \mathrm{F} n \mathrm{Hm}$ were synthesized from fluorene using the synthetic route illustrated in $\underline{\mathrm{Scheme}}$ $\underline{2}$.

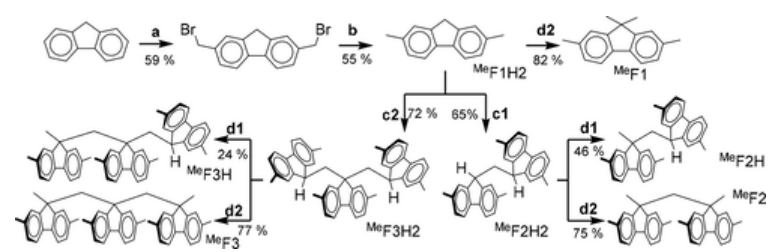

Scheme 2. Synthetic Route of ${ }^{\mathrm{Me}} \mathrm{F} n \mathrm{Hm}(n=1-3, m=0-2)$

Initial bromomethylation of fluorene was followed by debromination with lithium aluminum hydride (LAH) to produce 2,7-dimethylfluorene, $(29)$ which was converted to ${ }^{\mathrm{Me}} \mathrm{F} n \mathrm{H} 2$ ( $n=2$ and 3 ) by condensation with varying equivalent of paraformaldehyde and potassium tert-butyloxide as catalyst. Finally, monomethylation or doublemethylation was achieved to generate ${ }^{\mathrm{Me}} \mathrm{FnH}(n=2$ and 3$)$ and ${ }^{\mathrm{Me}} \mathrm{Fn}(n=1,2$ and 3$)$ in excellent yield using iodomethane as methylation reagent and tert-butyloxide as base. Structures of ${ }^{\mathrm{Me}} \mathrm{F} n \mathrm{Hm}$ were fully characterized by ${ }^{1} \mathrm{H} /{ }^{13} \mathrm{C}$ NMR, MALDI-TOF mass spectroscopies and X-ray crystallography of representative compounds (see Supporting Information for full details). Crystal structures of ${ }^{\mathrm{Me}} \mathrm{F} n(n=2,3)$ revealed the presence of fully $\pi$ stacked structures, while structures of ${ }^{\mathrm{Me}} \mathrm{F} 2 \mathrm{H}$ and ${ }^{\mathrm{Me}} \mathrm{F} 2 \mathrm{H} 2$ were found in an open T-shaped conformation stabilized by multiple $\mathrm{CH}-\pi$ interactions (Figure 3 ). Interestingly, ${ }^{\mathrm{Me}} \mathrm{F} 3 \mathrm{H} 2$ contains no stacked fragments but rather the open T-shaped configurations of the two bifluorene moieties (Figure 3 ).
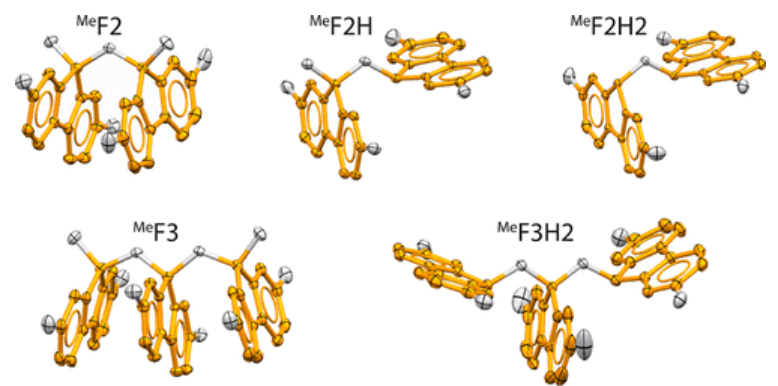

Figure 3. ORTEP diagrams ( $50 \%$ probability) of ${ }^{\mathrm{Me}} \mathrm{F} 2$, ${ }^{\mathrm{Me}} \mathrm{F} 2 \mathrm{H}$, ${ }^{\mathrm{Me}} \mathrm{F} 2 \mathrm{H} 2$, ${ }^{\mathrm{Me}} \mathrm{F} 3$, and ${ }^{\mathrm{Me}} \mathrm{F} 3 \mathrm{H} 2$. Hydrogen atoms have been omitted for the sake of clarity.

\section{Electrochemistry}

The redox properties of ${ }^{\mathrm{Me}} \mathrm{FnHm}$ were evaluated by electrochemical oxidation at a platinum electrode as a $2 \mathrm{mM}$ solution in $\mathrm{CH}_{2} \mathrm{Cl}_{2}$ containing $0.1 \mathrm{Mn} n-\mathrm{Bu}_{4} \mathrm{~N}^{+} \mathrm{PF}_{6}{ }^{-}$as the supporting electrolyte and referenced to ferrocene (i.e., $\mathrm{Fc} / \mathrm{Fc}^{+}$) as internal standard. Although ${ }^{\mathrm{Me}} \mathrm{F} 1 \mathrm{H} 2$ displays an irreversible $\mathrm{CV}$, the position of its oxidation wave is identical to that of ${ }^{\mathrm{Me}} \mathrm{F} 1$, which shows the reversible $\mathrm{CV}$ with the oxidation potential $E_{\text {ox }}=1.02 \mathrm{vs}$ $\mathrm{Fc} / \mathrm{Fc}^{+}$(Figure 4A). This suggests that the presence of methyl groups at 9 position does not impact the redox properties of the fluorenes, allowing us to establish whether ${ }^{\mathrm{Me}} \mathrm{F} n \mathrm{Hm}(m=1,2)$ undergo redox-controlled actuation by comparing their redox properties with those of model ${ }^{\mathrm{Me}} \mathrm{Fn}$, which are known to exist in the closed $(\pi$-stacked) conformation in both neutral and cation radical states.(17) 


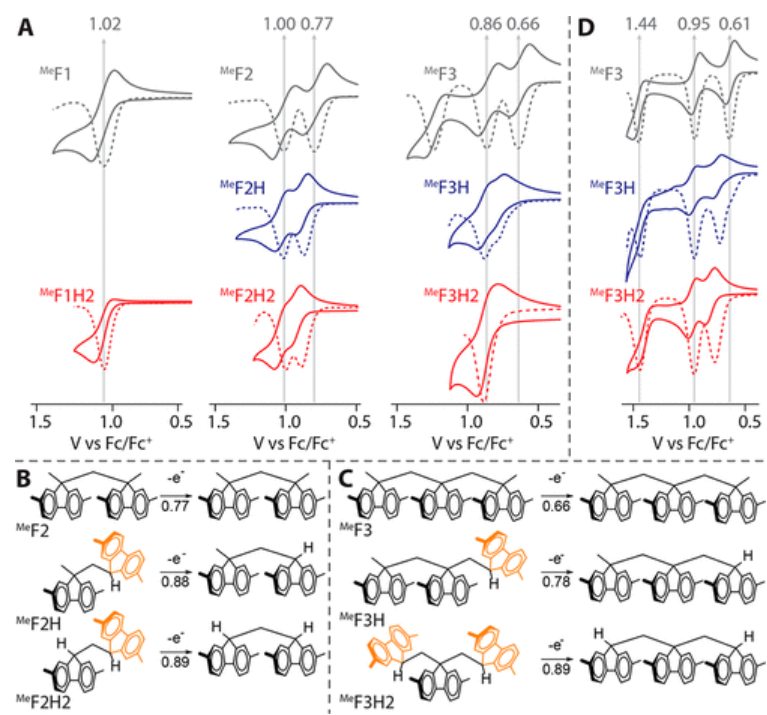

Figure 4. (A) Cyclic voltammograms (solid lines) and square wave voltammograms (dashed lines) of 2.0 $\mathrm{mM}{ }^{\mathrm{Me}} \mathrm{F} n \mathrm{Hm}$ in $\mathrm{CH}_{2} \mathrm{Cl}_{2}\left(0.1 \mathrm{M} \mathrm{n}-\mathrm{Bu}_{4} \mathrm{~N}^{+} \mathrm{PF}_{6}^{-}\right)$with a scan rate of $100 \mathrm{mV} / \mathrm{s}$. Values of the oxidation potentials of model $\left(\pi\right.$-stacked) ${ }^{\mathrm{Me}} \mathrm{F} n$ are indicated in gray color. Schematic description the oxidation-induced conformation transformation in (B) ${ }^{\mathrm{Me}} \mathrm{F} 2 \mathrm{Hm}$ and (C) ${ }^{\mathrm{Me}} \mathrm{F} 3 \mathrm{Hm}(m=0-2)$. (D) Cyclic voltammograms (solid lines) and square wave voltammograms (dashed lines) of $2.0 \mathrm{mM}$ MeF3Hm in $\mathrm{CH}_{2} \mathrm{Cl}_{2}\left(0.1 \mathrm{M} \mathrm{n}-\mathrm{Bu}_{4} \mathrm{~N}^{+} \mathrm{TFAB}^{-}\right)$with a scan rate of $100 \mathrm{mV} / \mathrm{s}$.

In the case of bifluorenes, the first oxidation potential $\left(E_{\text {ox1 }}\right)$ is the lowest for $\pi$-stacked ${ }^{\mathrm{Me}} \mathrm{F} 2$, while $E_{\text {ox } 1}$ of ${ }^{\mathrm{Me}} \mathrm{F} 2 \mathrm{H}$

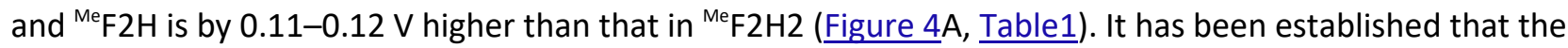
stabilization of the cationic charge (i.e., hole) is determined by the interplay between the energetic gain from delocalization and energetic penalty from structural, conformational and solvent reorganization. $(30,31)$ Therefore, the variation of $E_{0 \times 1}$ in the ${ }^{\mathrm{Me}} \mathrm{F} 2 \mathrm{Hm}$ series suggests a different degree of oxidation-induced reorganization between ${ }^{\mathrm{Me}} \mathrm{F} 2$ and ${ }^{\mathrm{Me}} \mathrm{F} 2 \mathrm{H} /{ }^{\mathrm{Me}} \mathrm{F} 2 \mathrm{H} 2$, and somewhat similar reorganization in ${ }^{\mathrm{Me}} \mathrm{F} 2 \mathrm{H}$ and ${ }^{\mathrm{Me}} \mathrm{F} 2 \mathrm{H} 2$.

Table 1. First ( $\left.E_{0 \times 1}\right)$ and Second ( $\left.E_{0 \times 2}\right)$ Oxidation Potentials of ${ }^{\mathrm{Me}} \mathrm{FnHm}$ Referenced to $\mathrm{Fc} / \mathrm{Fc}^{+}$with $0.1 \mathrm{M} n$ $\mathrm{Bu}_{4} \mathrm{~N}^{+} \mathrm{PF}_{6}{ }^{-}$as Supporting Electrolyte, Wavelengths of Maximum Absorption $(\lambda, \mathrm{nm})$, and Extinction Coefficients $\left(\varepsilon, \mathrm{M}^{-1} \mathrm{~cm}^{-1}\right)$ of ${ }^{\mathrm{Me}} \mathrm{FnHm}{ }^{+\cdot}$

\begin{tabular}{|c|c|c|c|c|}
\hline & $E_{\mathrm{ox} 1}$ & $E_{\text {ox2 }}$ & $\lambda, \mathrm{nm}$ & $\varepsilon, \mathrm{M}^{-1} \mathrm{~cm}^{-1}$ \\
\hline MeF1 & 1.02 & - & 655 & - \\
\hline${ }^{\mathrm{Me}} \mathrm{F} 1 \mathrm{H} 2$ & 1.02 & - & 655 & - \\
\hline MeF2 & 0.77 & 1.00 & 1455 & 5134 \\
\hline MeF2H & 0.88 & 1.00 & 1454 & 4839 \\
\hline MeF2H2 & 0.89 & 1.00 & 1494 & 4000 \\
\hline MeF3 & 0.66 & 0.86 & 1605 & 4040 \\
\hline MeF3H & 0.78 & 0.87 & 1528 & 3732 \\
\hline MeF3H2 & 0.89 & 0.89 & 1530 & 4826 \\
\hline
\end{tabular}

While in solution ${ }^{\mathrm{Me}} \mathrm{F} 2$ exists in $\pi$-stacked conformation in both neutral and cation radical states, neutral ${ }^{\mathrm{Me}} \mathrm{F} 2 \mathrm{H} 2$ and ${ }^{\mathrm{Me}} \mathrm{F} 2 \mathrm{H}$ exist in open conformations and upon oxidation undergo reorganization into a closed $\pi$-stacked conformation (Figure 4B), which requires an additional energetic penalty to overcome the conformational reorganization. As the first oxidation transforms ${ }^{\mathrm{Me}} \mathrm{F} 2 \mathrm{H} 2$ and ${ }^{\mathrm{Me}} \mathrm{F} 2 \mathrm{H}$ into a $\pi$-stacked conformation, their second oxidation occurs at the same potential as in ${ }^{\mathrm{Me}} \mathrm{F} 2$ (Figure 4A). 
As for the bifluorenes, ${ }^{\mathrm{Me}} \mathrm{F} 3$ displays the lowest first oxidation potential across the ${ }^{\mathrm{Me}} \mathrm{F} 3 \mathrm{H} m$ series due to the stacked arrangement of fluorenes in both neutral and cation radical states, which affords efficient hole stabilization (Figure 4C). The first oxidation potential of ${ }^{\mathrm{Me}} \mathrm{F} 3 \mathrm{H}$ is by $0.12 \mathrm{~V}$ higher than that of ${ }^{\mathrm{Me}} \mathrm{F} 3$ due to the additional oxidation-induced reorganization associated with bringing one fluorene moiety into the stacked arrangement. In ${ }^{\mathrm{Me}} \mathrm{F} 3 \mathrm{H} 2$, an additional $0.11 \mathrm{~V}$ as compared to ${ }^{\mathrm{Me}} \mathrm{F} 3 \mathrm{H}$ (or 0.23 as compared to ${ }^{\mathrm{Me}} \mathrm{F} 3$ ) is required to bring two fluorene moieties into the stack. On the basis of the analysis of the first oxidation potentials of ${ }^{\mathrm{Me}} \mathrm{F} 2 \mathrm{Hm}$ and ${ }^{\mathrm{Me}} \mathrm{F} 3 \mathrm{Hm}$ series (Table1) we conclude that the energetic cost of bringing one fluorene into the stacked arrangement upon the first oxidation lies in 0.11-0.12 V range. The second oxidation potential is nearly identical across the ${ }^{\mathrm{Me}} \mathrm{F} 3 \mathrm{Hm}$ series (Table1) suggesting that after the first electron transfer all three compounds indeed exist in a fully $\pi$-stacked conformation.

The increasing reorganization penalty in going from ${ }^{\mathrm{Me}} \mathrm{F} 3$ to ${ }^{\mathrm{Me}} \mathrm{F} 3 \mathrm{H}$ to ${ }^{\mathrm{Me}} \mathrm{F} 3 \mathrm{H} 2$ is clearly seen by inspection of their CVs, which show well-separated first and second oxidation waves in ${ }^{\mathrm{Me}} \mathrm{F} 3$, two closely spaced waves in ${ }^{\mathrm{Me}} \mathrm{F} 3 \mathrm{H}$, and two coalesced waves in ${ }^{\mathrm{Me}} \mathrm{F} 3 \mathrm{H} 2$ (Figure 4A). However, it is well-known that the separation between first and second oxidation waves is modulated by the ion pairing of the oxidized species with the counteranions. $(32,33)$ In order to reduce the effects of ion pairing we performed an additional electrochemical analysis with the bulky tetrakis(pentafluorophenyl)borate (TFAB ${ }^{-}$) anion. The resulting $\mathrm{CV}$ in Figure 4D show two well separated oxidation waves in all three cases, with the splitting between two waves decreasing when going from ${ }^{\mathrm{Me}} \mathrm{F} 3$ to ${ }^{\mathrm{Me}} \mathrm{F} 3 \mathrm{H}$ to ${ }^{\mathrm{Me}} \mathrm{F} 3 \mathrm{H} 2$, in agreement with the above analysis.

\section{Generation of Cation Radicals of ${ }^{\mathrm{Me}} \mathrm{F} n \mathrm{Hm}$}

In order to further probe whether upon oxidation of ${ }^{\mathrm{Me}} \mathrm{FnHm}$ the corresponding cation radical exists in a fully $\pi$ stacked conformation, we resorted to electronic spectroscopy. Cation radicals of ${ }^{\mathrm{Me}} \mathrm{FnHm}$ were generated in solution via quantitative $(34,35)$ redox titrations using a stable one-electron aromatic oxidant, such as [THEO ${ }^{+*} \mathrm{SbCl}_{6}^{-}$] (1,4,5,8-dimethano-1,2,3,4,5,6,7,8-octahydro-9,10-dimethoxyanthracene hexachloroantimonate; $\left.E_{\text {red }}=0.67 \mathrm{~V} \mathrm{vs} \mathrm{Fc} / \mathrm{Fc}^{+}, \lambda_{\max }=518, \varepsilon=7300 \mathrm{M}^{-1} \mathrm{~cm}^{-1}\right)$ and $\left[\mathrm{NAP}^{+*} \mathrm{SbCl}_{6}^{-}\right](\mathrm{NAP}=$ $1,1,4,4,7,7,10,10$-octamethyl-1,2,3,4,7,8,9,10-octahydrotetracene, $E_{\mathrm{red}}=0.94 \mathrm{~V} \mathrm{vs} \mathrm{Fc} / \mathrm{Fc}^{+}, \lambda_{\max }=673 \mathrm{~nm}, \varepsilon_{\max }=$ $9300 \mathrm{~cm}^{-1} \mathrm{M}^{-1}$ ). Each redox titration experiment was carried out by an incremental addition of substoichiometric amounts of ${ }^{\mathrm{Me}} \mathrm{FnHm}$ to the solution of oxidant (i.e., $\mathrm{THEO}^{+\bullet}$ or $\mathrm{NAP}^{+*}$ ). At each titration point a numerical deconvolution procedure was employed to produce mole fraction plots of each species involved in the redox reaction.

Figure 5A shows the electronic absorption spectra obtained upon an incremental (substoichiometric) addition of a $\mathrm{CH}_{2} \mathrm{Cl}_{2}$ solution of ${ }^{\mathrm{Me}} \mathrm{F} 3 \mathrm{H}$ to a solution of $\left[\mathrm{NAP}^{+\cdot} \mathrm{SbCl}_{6}^{-}\right.$] at $22^{\circ} \mathrm{C}$. A plot of the mole fractions of $\mathrm{NAP}^{+\bullet}$ and ${ }^{\mathrm{Me}} \mathrm{F}_{3} \mathrm{H}^{+\bullet}$ against the added equivalents of ${ }^{\mathrm{Me}} \mathrm{F} 3 \mathrm{H}^{+\bullet}$ established a 1:1 stoichiometry of the redox reaction (Figure $5 \mathrm{~B}$ ), i.e. the one-electron oxidation of ${ }^{\mathrm{Me}} \mathrm{F} 3 \mathrm{H}$ to ${ }^{\mathrm{Me}} \mathrm{F} \mathrm{H}^{+\bullet}$ and reduction of NAP ${ }^{+\bullet}$ to NAP can be described by an equilibrium: $\mathrm{NAP}^{+\bullet}+{ }^{\mathrm{Me}} \mathrm{F} 3 \mathrm{H} \rightleftarrows \mathrm{NAP}+{ }^{\mathrm{Me}} \mathrm{F} 3 \mathrm{H}^{+\bullet}$. Following this approach cation radical spectra of the ${ }^{\mathrm{Me}} \mathrm{F} \mathrm{Hm}^{+\bullet}$ have been generated and the complete details are shown in the Supporting Information. 

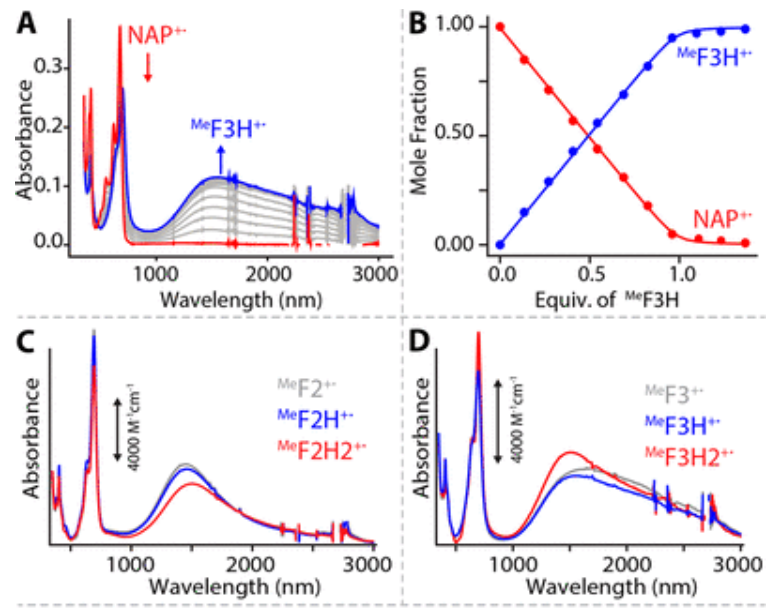

E

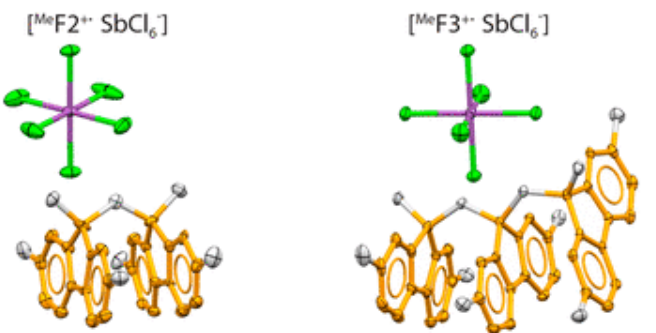

Figure 5. (A) Spectral changes observed upon the reduction of $0.024 \mathrm{mM} \mathrm{NAP+ \cdot}$ in $\mathrm{CH}_{2} \mathrm{Cl}_{2}$ by incremental addition of $1.04 \mathrm{mM}$ solution of ${ }^{\mathrm{Me}} \mathrm{F} 3 \mathrm{H} 2$ in $\mathrm{CH}_{2} \mathrm{Cl}_{2}$ at $22^{\circ} \mathrm{C}$. (B) Plot of the mole fractions of $\mathrm{NAP}^{+\bullet}$ (red) and $\mathrm{MeF}^{\circ} \mathrm{H}^{+\bullet}$ (black) against added equivalents of neutral ${ }^{\mathrm{Me}} \mathrm{F} 3 \mathrm{H} 2$. Symbols represent experimental points, while the solid lines show best-fit to experimental points using $\Delta G=E_{\text {ox }}\left(\mathrm{MeF}^{\mathrm{H}} \mathrm{H} 2\right)-E_{\text {red }}\left(\mathrm{NAP}^{+\cdot}\right)=3 \mathrm{mV}$. (C and D) Electronic absorption

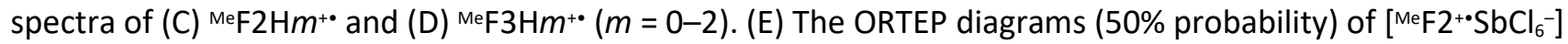
and $\left[\mathrm{MeF}^{\mathrm{S}} \mathrm{SbCl}_{6}{ }^{-}\right]$. Hydrogen atoms have been omitted for the sake of clarity.

Electronic absorption spectra of ${ }^{\mathrm{Me}} \mathrm{F} 2 \mathrm{Hm}^{+\bullet}$ showed nearly identical intervalence transitions centered at $\sim 1500$ $\mathrm{nm}$ (Figure $5 \mathrm{C}$ ), suggesting that the structures of ${ }^{\mathrm{Me}} \mathrm{F} 2 \mathrm{H}^{+\cdot}$ and ${ }^{\mathrm{Me}} \mathrm{F} 2 \mathrm{H}^{+*}$ are identical to that of ${ }^{\mathrm{Me}} \mathrm{F} 2^{+\bullet}$, i.e., the $\pi$ stacked conformation. Similarly, absorption spectra of ${ }^{\mathrm{Me}} \mathrm{F} 3 \mathrm{Hm}^{+\cdot}$ display an intervalence band that is red-shifted by 30-100 nm as compared to the corresponding band in ${ }^{\mathrm{Me}} \mathrm{F} 2 \mathrm{Hm}^{+\bullet}$ series (Figure $5 \mathrm{D}$ ), signifying extended hole delocalization across the $\pi$-stacked arrangement. Interestingly, all three ${ }^{\mathrm{Me}} \mathrm{F} 3 \mathrm{Hm}^{+\bullet}$ exhibit a characteristic tail of in their absorption band extending beyond $3000 \mathrm{~nm}$.

Preparative isolation of the polyfluorene cation radicals was carried out by chemical oxidation using nitrosonium hexachloroantimonate, i.e., $\left[\mathrm{NO}^{+} \mathrm{SbCl}_{6}^{-}\right]$. Solution of polyfluorene and $\left[\mathrm{NO}^{+} \mathrm{SbCl}_{6}^{-}\right]$in anhydrous $\mathrm{CH}_{2} \mathrm{Cl}_{2}$ with $1: 1$ ratio was stirred under an argon atmosphere at $\sim 0{ }^{\circ} \mathrm{C}$, while bubbling argon through the solution to entrain gaseous nitric oxide. The resulting solution was carefully layered with toluene and stored in a refrigerator $(-10$ ${ }^{\circ} \mathrm{C}$ ) for 2 days, which in case of $\left[{ }^{\mathrm{Me}} \mathrm{F}^{+\cdot} \mathrm{SbCl}_{6}^{-}\right]$and $\left[{ }^{\mathrm{Me}} \mathrm{F}^{+*} \mathrm{SbCl}_{6}^{-}\right]$yielded single crystals that were suitable for X-ray crystallography. Both structures reveal the $\pi$-stacked arrangement of the fluorenes (Figure $5 \mathrm{E})$. Unfortunately, recrystallization of mono and nonmethylated species, i.e., $\left[{ }^{\mathrm{Me}} \mathrm{F} 2 \mathrm{Hm}^{+\bullet} \mathrm{SbCl}_{6}^{-}\right]$and $\left[{ }^{\mathrm{Me}} \mathrm{F}_{3} \mathrm{Hm}^{+\bullet} \mathrm{SbCl}_{6}^{-}\right](m=1,2)$, was thus far unsuccessful due to instability of the resulting cation radicals.

To conclude, in this manuscript, we have designed and synthesized a series of cofacially arrayed polyfluorenes with varied end-capping groups ( $\left.{ }^{\mathrm{Me}} \mathrm{F} n \mathrm{H} m, n=1-3, m=0-2\right)$ from readily available fluorene in excellent yield. We have shown with the aid of NMR, X-ray crystallography and DFT calculations that in the neutral state the conformation of ${ }^{\mathrm{Me}} \mathrm{FnHm}$ is highly dependent on the end-capping groups and the environment. For example, when both end-capping groups are methyl, fully $\pi$-stacked structure is adopted in the gas, liquid, and solid states. In contrast, when one or both of the end-capping groups are hydrogens, W-shaped conformation is 
favored in solution, while the T-shaped conformer was found in the solid state as has been demonstrated for the case of ${ }^{\mathrm{Me}} \mathrm{F} 2 \mathrm{H}$ and ${ }^{\mathrm{Me}} \mathrm{F} 2 \mathrm{H} 2$. However, upon (electro)chemical oxidation ${ }^{\mathrm{Me}} \mathrm{FnHm}$ is transformed into the fully $\pi$ stacked conformation irrespective of the end-capping groups, as evidenced from the electronic spectroscopy and X-ray crystallography of the cation radicals. Accordingly, we have shown that ${ }^{\mathrm{Me}} \mathrm{FnH}$ and ${ }^{\mathrm{Me}} \mathrm{FnH} 2$ undergo a redox-controlled mechanical actuation that is driven by the charge-resonance stabilization of the cationic charge. These findings will aid in the design of novel wire-like cofacially arrayed systems capable to undergo the redox-controlled actuation.

\section{Supporting Information}

The Supporting Information is available free of charge on the ACS Publications website at DOI: $10.1021 /$ acs.jpclett.8b01918.

- Synthetic details, characterization data, details on generation of the cation radicals, crystal structure data and computational details (PDF)

- $\quad$ pdf

$0 \quad \underline{z z 8 b 01918 \text { si } 001 . p d f(6.03 \mathrm{MB})}$

\section{Acknowledgments}

We thank the NSF (CHE-1508677) and NIH (R01-HL112639-04) for financial support and William E. Geiger (The University of Vermont) for kindly donating us a sample of $n-\mathrm{Bu}_{4} \mathrm{~N}^{+} T F A B^{-}$. The calculations were performed on the high-performance computing cluster Père at Marquette University and XSEDE.

\section{References}

$\underline{1}$ Chen, D.; Pei, Q. Electronic Muscles and Skins: A Review of Soft Sensors and Actuators. Chem. Rev. 2017, 117, 11239-11268, DOI: 10.1021/acs.chemrev.7b00019

$\underline{2}$ Yu, H.-H.; Swager, T. M. Molecular Actuators - Designing Actuating Materials at the Molecular Level. IEEE J. Oceanic Eng. 2004, 29, 692- 695, DOI: 10.1109/JOE.2004.833141

3 Manrique-Juarez, M. M.; Mathieu, F.; Shalabaeva, V.; Cacheux, J.; Rat, S.; Nicu, L.; Leïchlé, T.; Salmon, L.; Molnár, G.; Bousseksou, A. A Bistable Microelectromechanical System Actuated by Spin-Crossover Molecules. Angew. Chem. 2017, 129, 8186-8190, DOI: 10.1002/ange.201702739

$\underline{4}$ Shepherd, H. J.; Gural'skiy, I. A.; Quintero, C. M.; Tricard, S.; Salmon, L.; Molnár, G.; Bousseksou, A. Molecular Actuators Driven by Cooperative Spin-state Switching. Nat. Commun. 2013, 4, 2607, DOI: 10.1038/ncomms3607

$\underline{\mathbf{5}}$ Rossner, C.; Glatter, O.; Vana, P. Stimulus-Responsive Planet-Satellite Nanostructures As Colloidal Actuators: Reversible Contraction and Expansion of the Planet-Satellite Distance. Macromolecules 2017, 50, 7344- 7350, DOI: 10.1021/acs.macromol.7b01267

$\underline{6}$ Li, C.; Gunari, N.; Fischer, K.; Janshoff, A.; Schmidt, M. New Perspectives for the Design of Molecular Actuators: Thermally Induced Collapse of Single Macromolecules From Cylindrical Brushes to Spheres. Angew. Chem., Int. Ed. 2004, 43, 1101-1104, DOI: 10.1002/anie.200352845

Z Ohtake, T.; Tanaka, H. Redox-induced Actuation in Macromolecular and Self-assembled Systems. Polym. J. 2016, 48, 25, DOI: 10.1038/pj.2015.75 
$\underline{8}$ Ohtake, T.; Tanaka, H.; Matsumoto, T.; Kimura, M.; Ohta, A. Redox-driven Molecular Switches Consisting of Bis (benzodithiolyl) Bithienyl Scaffold and Mesogenic Moieties: Synthesis and Complexes with Liquid Crystalline Polymer. J. Org. Chem. 2014, 79, 6590-6602, DOI: 10.1021/jo501072u

9 Shukla, R.; Thakur, K.; Chebny, V. J.; Reid, S. A.; Rathore, R. Direct Observation of Electron-transfer-induced Conformational Transformation (molecular Actuation) in a Bichromophoric Electron Donor. J. Phys. Chem. B 2010, 114, 14592-14595, DOI: 10.1021/jp102357w

10 Chebny, V. J.; Shukla, R.; Lindeman, S. V.; Rathore, R. Molecular Actuator: Redox-controlled Clam-like Motion in a Bichromophoric Electron Donor. Org. Lett. 2009, 11, 1939-1942, DOI: 10.1021/ol900371m

$\underline{11}$ Rathore, R.; Chebny, V. J.; Kopatz, E. J.; Guzei, I. A. Redox-Induced Transformation From An Extended to a חStacked Conformer in Acyclic Bis (catecholacetal) S of Acetylacetone. Angew. Chem., Int. Ed. 2005, 44, 2771-2774, DOI: 10.1002/anie.200463103

12 Song, C.; Swager, T. M. Pi-dimer Formation As the Driving Force for Calix[4]arene-based Molecular Actuators. Org. Lett. 2008, 10, 3575-3578, DOI: 10.1021/ol8013039

13 Uhler, B.; Ivanov, M. V.; Kokkin, D.; Reilly, N.; Rathore, R.; Reid, S. A. Effect of Facial Encumbrance on Excimer Formation and Charge Resonance Stabilization in Model Bichromophoric Assemblies. J. Phys. Chem. C 2017, 121, 15580-15588, DOI: 10.1021/acs.jpcc.7b04255

14 Navale, T. S.; Thakur, K.; Vyas, V. S.; Wadumethrige, S. H.; Shukla, R.; Lindeman, S. V.; Rathore, R. Charge Delocalization in Self-assembled Mixed-valence Aromatic Cation Radicals. Langmuir 2012, 28, 71-83, DOI: 10.1021/la202611w

15 Zadorozhnaya, A. A.; Krylov, A. I. Ionization-Induced Structural Changes in Uracil Dimers and Their Spectroscopic Signatures. J. Chem. Theory Comput. 2010, 6, 705- 717, DOI: 10.1021/ct900515a

16 Pieniazek, P. A.; Krylov, A. I.; Bradforth, S. E. Electronic Structure of the Benzene Dimer Cation. J. Chem. Phys. 2007, 127, 044317, DOI: 10.1063/1.2749506

17 Rathore, R.; Abdelwahed, S. H.; Guzei, I. A. Synthesis, Structure, and Evaluation of the Effect of Multiple Stacking on the Electron-donor Properties of Pi-stacked Polyfluorenes. J. Am. Chem. Soc. 2003, 125, 8712-8713, DOI: 10.1021/ja035518s

18 Nakano, T.; Yade, T. Synthesis, Structure, and Photophysical and Electrochemical Properties of a Pi-stacked Polymer. J. Am. Chem. Soc. 2003, 125, 15474- 15484, DOI: 10.1021/ja037836x

19 Vura-Weis, J.; Abdelwahed, S. H.; Shukla, R.; Rathore, R.; Ratner, M. A.; Wasielewski, M. R. Crossover From Single-step Tunneling to Multistep Hopping for Molecular Triplet Energy Transfer. Science 2010, 328, 1547- 1550, DOI: 10.1126/science.1189354

20 Talipov, M. R.; Ivanov, M. V.; Reid, S. A.; Rathore, R. Two's Company, Three's a Crowd: Exciton Localization in Cofacially Arrayed Polyfluorenes. J. Phys. Chem. Lett. 2016, 7, 2915-2920, DOI: 10.1021/acs.jpclett.6b01268

21 Humeniuk, A.; Mitrić, R. DFTBaby: A Software Package for Non-adiabatic Molecular Dynamics Simulations Based on Long-range Corrected Tight-binding TD-DFT(B). Comput. Phys. Commun. 2017, 221, 174- 202, DOI: 10.1016/j.cpc.2017.08.012

22 Coropceanu, V.; Nakano, T.; Gruhn, N. E.; Kwon, O.; Yade, T.; Katsukawa, K.; Brédas, J. L. Probing Charge Transport in Pi-stacked Fluorene-based Systems. J. Phys. Chem. B 2006, 110, 9482-9487, DOI: 10.1021/jp060855j

$\underline{23}$ Ivanov, M. V.; Reilly, N. J.; Uhler, B.; Kokkin, D.; Rathore, R.; Reid, S. A. Cofacially-Arrayed Polyfluorenes: Spontaneous Formation of $\Pi$-Stacked Assemblies in the Gas-Phase. J. Phys. Chem. Lett. 2017, 8, 5272- 5276, DOI: 10.1021/acs.jpclett.7b02627

24 Balmer, F. A.; Trachsel, M. A.; van der Avoird, A.; Leutwyler, S. The Elusive S2 State, the S1/S2 Splitting, and the Excimer States of the Benzene Dimer. J. Chem. Phys. 2015, 142, 234306, DOI: 10.1063/1.4922608

$\underline{\mathbf{2 5}}$ Sinnokrot, M. O.; Valeev, E. F.; Sherrill, C. D. Estimates of the Ab Initio Limit for Pi-pi Interactions: The Benzene Dimer. J. Am. Chem. Soc. 2002, 124, 10887- 10893, DOI: 10.1021/ja025896h 
$\underline{26}$ Hobza, P.; Selzle, H. L.; Schlag, E. W. Potential Energy Surface for the Benzene Dimer. Results of Ab Initio CCSD (T) Calculations Show Two Nearly Isoenergetic Structures: T-shaped and Parallel-displaced. J. Phys. Chem. 1996, 100, 18790- 18794, DOI: 10.1021/jp961239y

27 Zhao, Y.; Truhlar, D. G. The M06 Suite of Density Functionals for Main Group Thermochemistry, Thermochemical Kinetics, Noncovalent Interactions, Excited States, and Transition Elements: Two New Functionals and Systematic Testing of Four M06-class Functionals and 12 Other Functionals. Theor. Chem. Acc. 2008, 120, 215- 241, DOI: 10.1007/s00214-007-0310-x

$\underline{28}$ Ditchfield, R.; Hehre, W. J.; Pople, J. A. Self-consistent Molecular-orbital Methods. IX. An Extended Gaussiantype Basis for Molecular-orbital Studies of Organic Molecules. J. Chem. Phys. 1971, 54, 724- 728, DOI: 10.1063/1.1674902

$\underline{29}$ Haenel, M. W.; Irngartinger, H.; Krieger, C. Transanular Interaction in [m.n]phanes. 27. Models for Excimers and Exciplexes: [2,2]phanes of Fluorene, 9-fluorenone, and 9-fluorenyl Anion. Chem. Ber. 1985, 118, 144- 162, DOI: 10.1002/cber.19851180115

30Talipov, M. R.; Boddeda, A.; Timerghazin, Q. K.; Rathore, R. Key Role of End-capping Groups in Optoelectronic Properties of Poly-p-phenylene Cation Radicals. J. Phys. Chem. C 2014, 118, 21400- 21408, DOI: 10.1021/jp5082752

31 Ivanov, M. V.; Talipov, M. R.; Boddeda, A.; Abdelwahed, S. H.; Rathore, R. Hückel Theory+ Reorganization Energy= Marcus-Hush TheoryBreakdown of the 1/n Trend in $\Pi$-Conjugated Poly-p-phenylene Cation Radicals Is Explained. J. Phys. Chem. C 2017, 121, 1552- 1561, DOI: 10.1021/acs.jpcc.6b12111

32 Barrière, F.; Geiger, W. E. Use of Weakly Coordinating Anions to Develop An Integrated Approach to the Tuning of $\Delta \mathrm{E} 1 / 2$ Values by Medium Effects. J. Am. Chem. Soc. 2006, 128, 3980-3989, DOI: 10.1021/ja058171x

33 Geiger, W. E.; Barrière, F. Organometallic Electrochemistry Based on Electrolytes Containing Weaklycoordinating Fluoroarylborate Anions. Acc. Chem. Res. 2010, 43, 1030-1039, DOI: 10.1021/ar1000023

34 Talipov, M. R.; Boddeda, A.; Hossain, M. M.; Rathore, R. Quantitative Generation of Cation Radicals and Dications Using Aromatic Oxidants: Effect of Added Electrolyte on the Redox Potentials of Aromatic Electron Donors. J. Phys. Org. Chem. 2016, 29, 227- 233, DOI: 10.1002/poc.3523

35 Talipov, M. R.; Hossain, M. M.; Boddeda, A.; Thakur, K.; Rathore, R. A Search for Blues Brothers: X-ray Crystallographic/spectroscopic Characterization of the Tetraarylbenzidine Cation Radical As a Product of Aging of Solid Magic Blue. Org. Biomol. Chem. 2016, 14, 2961-2968, DOI: 10.1039/C6OB00140H 